\title{
Insulin-like growth factor receptor-1 expression predicts postoperative recurrence in adenocarcinoma of the lung
}

\author{
MAKOTO NAKAGAWA, HIDETAKA URAMOTO, HIDEHIKO SHIMOKAWA, \\ TAKAMITSU ONITSUKA, TAKESHI HANAGIRI and FUMIHIRO TANAKA
}

Second Department of Surgery, School of Medicine, University of Occupational and Environmental Health, Kitakyushu, Japan

Received February 25, 2011; Accepted April 15, 2011

DOI: $10.3892 /$ etm.2011.258

\begin{abstract}
Not all patients with lung cancer require postoperative adjuvant chemotherapy after a complete resection. However, no useful markers exist for either selecting appropriate candidates or for predicting clinical recurrence. The purpose of the present study was to clarify the clinical role of insulin-like growth factor receptor-1 (IGFR1) in lung adenocarcinoma. Tumor specimens were collected from 182 patients who underwent a complete resection for adenocarcinoma of the lung. The expression of IGFR1 was evaluated by immunohistochemistry. The genetic status of the epidermal growth factor receptor (EGFR) and K-ras genes was also investigated by PCR-based analyses. Immunohistochemistry and real-time PCR assays were used to evaluate the MET gene association with tyrosine phosphorylation and hepatocyte growth factor (HGF) status, and amplification, respectively. Positive expression of IGFR1 was detected in 43 (23.6\%) of the 182 cases. A positive IGFR1 expression was also identified in $12(42.9 \%)$ and $31(20.1 \%)$ of the patients with and without recurrence, respectively $(p=0.009)$. Logistic regression models indicated that positive staining for IGFR1 expression was an independent factor associated with tumor recurrence. IGFR1 expression was associated with a poorer disease-free survival (DFS). Multivariate analysis demonstrated positive IGFR1 expression to be independently associated with an increased risk for poor DFS. The tumors appearing positive for IGFR1 were more frequent among those with K-ras mutations when
\end{abstract}

Correspondence to: Dr Hidetaka Uramoto, Second Department of Surgery, School of Medicine, University of Occupational and Environmental Health, 1-1 Iseigaoka, Yahatanishi-ku, Kitakyushu 807-8555, Japan

E-mail: hidetaka@med.uoeh-u.ac.jp

Abbreviations: IGFR1, insulin-like growth factor receptor-1; EGFR, epidermal growth factor receptor; HGF, hepatocyte growth factor; DFS, disease free survival; NSCLC, non-small cell lung cancer; IGF, insulin-like growth factor; IHC, immunohistochemical; 95\% CI, 95\% confidence interval; OR, odds ratio

Key words: insulin-like growth factor receptor-1, recurrence, lung cancer, adenocarcinoma compared with the wild-type group. IGFR1 expression was associated with reduced DFS correlating with postoperative recurrence. Therefore, the expression status of IGFR1 can be a candidate surrogate marker to select patients who may benefit from adjuvant chemotherapy.

\section{Introduction}

Lung cancer is the leading cause of cancer-related death in the world (1). The incidence of adenocarcinoma, one of the major histological subtypes of non-small cell lung cancer (NSCLC), is increasing (2). The prognosis is dismal as the 5 -year survival is only approximately $50 \%$, even in patients who achieve complete surgical resection (3). This suggests that occult metastases are present at the time of surgical intervention. As a consequence, adjuvant chemotherapy is required (4). However, the 5-year survival rate of patients with resected stage IB NSCLC is $74 \%$ without adjuvant chemotherapy, suggesting that not all patients require chemotherapy after a complete resection (5). Therefore, it is necessary to identify patients who may benefit the most from post-operative adjuvant chemotherapy to, not only precisely select the patients who require additional treatment, but also to prevent the occurrence of adverse events in patients who do not require treatment (4). Therefore, it is important to evaluate the biological and molecular characteristics of lung adenocarcinoma to identify the factors related to recurrence following surgery. However, there are currently no useful markers that predict clinical recurrence.

Insulin-like growth factor receptor-1 (IGFR1) is a transmembrane heterotetrameric protein implicated in promoting oncogenic transformation, growth and survival of cancer cells (6). The binding of insulin-like growth factor (IGF) to the extracellular domain of IGFR1 activates the tyrosine kinase activity of IGFR1 and triggers a cascade of reactions involving signal transduction pathways (7). The overexpression of IGFR1 has been shown to correlate with a poor prognosis in NSCLC patients (8). However, the precise reason for the poor prognosis remains unclear. Therefore, we hypothesized that IGFR1 may be a useful indicator of tumor recurrence in patients following complete resection. This is the first molecular analysis of the IGFR1 status and tumor recurrence related to the disease-free survival (DFS) of patients with lung adenocarcinoma, and association of EGFR-related molecules. 


\section{Materials and methods}

Patients, clinical features and follow-up. Tumor samples were obtained from 296 patients with primary lung adenocarcinoma who had undergone a surgical resection between 2003 and 2007 at the Second Department of Surgery. Nine of these patients were stage IV and 25 underwent an incomplete resection. The tumor samples from 80 patients were too small to evaluate by immunohistochemical (IHC) staining. As a result, 114 patients were excluded from further analysis and 182 tumor specimens were evaluated. All the patients were Japanese, including 100 males and 82 females in this series, with a mean age of 68.5 years (range 23-88). No patients had received either chemotherapy or radiotherapy prior to the resection. There were 75 never smokers, 50 former and 57 current smokers. Former smokers were defined as those who quit smoking at least 3 years before the time of surgery. The tumor stage was classified according to the TNM Classification for Lung Cancer (7th edition) (9). According to the pathological stage, 105 patients had tumors of stage IA, 39 of IB, 13 of IIA, 6 of IIB, 16 of IIIA and 3 of stage IIIB.

The patients were followed up every month during the first postoperative year and at approximately 2- to 4-month intervals thereafter. The evaluations included a physical examination, chest roentgenography, an analysis of blood chemistry and measurements of tumor markers, such as CEA, SCC and CYFRA. Chest and abdominal computed tomography, brain magnetic resonance imaging and a bone scintiscan were performed every 6 months for 3 years after surgery. Additional examinations were performed when any symptoms or signs of recurrence were detected. Twentyseven (14.8\%) patients received adjuvant chemotherapy, 18 received carboplatin plus paclitaxel, 7 received carboplatin plus gemcitabine and 2 received tegafur-uracil. A followup was conducted in all patients, and the median follow-up period was 68.7 months. One hundred and forty-three patients were alive and free of cancer at the last follow-up, while 11 patients had died of other causes without evidence of cancer, 12 patients were alive with recurrent cancer and 16 patients had died of cancer.

Immunohistochemical staining and evaluation for IGFRI. The institutional review board approved the study protocol, and informed consent for the use of the tumor specimens was obtained either from the patients or from the patients' legal guardians. IHC staining was conducted using serial sections from the same paraffin-embedded blocks according to previously described methods $(10,11)$. All specimens were stained with $\mathrm{H} \& \mathrm{E}$ for the histological diagnosis. Briefly, the sections were placed in $0.01 \mathrm{~mol} / 1$ citrate buffer $(\mathrm{pH} 6.0)$ and autoclaved at $121^{\circ} \mathrm{C}$ for $10 \mathrm{~min}$. They were treated with $3 \%$ $\mathrm{H}_{2} \mathrm{O}_{2}$ for 5 min to block the endogenous peroxidase activity. The primary antibody used was a mouse monoclonal antibody against human IGFR1 (3C8B1; Abcam, Cambridge, MA, USA) (12), diluted 1:500 in PBS and incubated for $18 \mathrm{~h}$ at $4^{\circ} \mathrm{C}$. Thereafter, IHC staining was performed by the labeled polymer method (Histofine Simple Stain MAX-PO kit; Nichirei, Tokyo, Japan) according to the manufacturer's instructions $(13,14)$. The positive and negative controls were
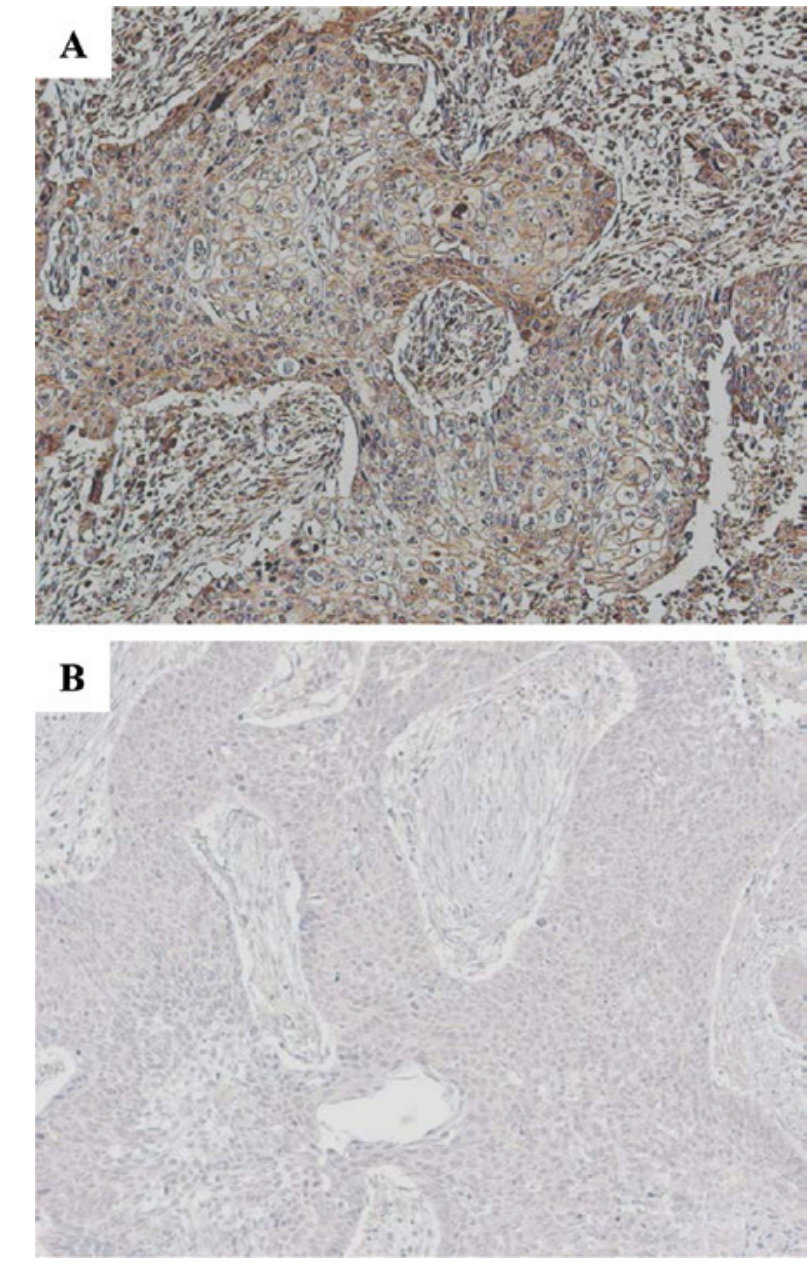

Figure 1. Representative IHC staining. (A) Positive staining for IGFR1 with brown-stained membrane is viewed at low power (original magnification, $\mathrm{x} 100)$. (B) Negative staining for IGFR1 is shown.

processed using primary lung squamous cell carcinoma specimens expressing IGFR1 and by the exclusion of the primary antibody, respectively. IHC was considered to be positive only when a distinct cell membrane staining was evident (Fig. 1A). An average of 1,500 cells were evaluated per section utilizing a semi-quantitative grading system based on four stages: 0 , no staining; $1+$, staining in $1-10 \%$ of the cells; $2+$, staining in $11-25 \%$ of the cells; $3+$, staining in $>25 \%$ of the cells. A cutoff value of $10 \%$ positive cells (stages of $2+$ and $3+$ ) was used in order to avoid inclusion of scattered positivity of the same intensity found in the normal bronchial tissue (15). The slides were independently examined by two of the investigators (M.N. and H.S.) who were blinded to the clinicopathological data. Any discrepancy between the two investigators was resolved by their simultaneous examination using a double-headed microscope. The correlation of IGFR1 status and the genetic factors included below were also analyzed.

Detection and quantification of EGFR-related signaling molecules. The genomic DNA was extracted from each tumor by previously described methods (16). The EGFR and K-ras mutations were investigated by PCR-based analyses (13). The status of phosphorylation of MET and HGF was examined by 
Table I. Relationship between the IGF1R expression and clinicopathological characteristics.

\begin{tabular}{|c|c|c|c|}
\hline \multirow[t]{2}{*}{ Variables } & \multirow[t]{2}{*}{ No. of patients } & \multicolumn{2}{|c|}{ IGF1R expression } \\
\hline & & $\begin{array}{c}\text { Positive } \\
\text { n (\%) }\end{array}$ & $\begin{array}{c}\text { Negative } \\
\mathrm{n}\end{array}$ \\
\hline Total patients & 182 & $43(23.6)$ & 139 \\
\hline \multicolumn{4}{|l|}{ Gender } \\
\hline Male & 100 & $25(25.0)$ & 75 \\
\hline Female & 82 & $18(22.0)$ & 64 \\
\hline \multicolumn{4}{|l|}{ Age (years) } \\
\hline$<68$ & 74 & $18(24.3)$ & 56 \\
\hline$\geq 68$ & 108 & $25(23.1)$ & 83 \\
\hline \multicolumn{4}{|c|}{ Pathologic stage } \\
\hline IA & 105 & $24(22.9)$ & 81 \\
\hline IB-III & 77 & $19(24.7)$ & 58 \\
\hline \multicolumn{4}{|l|}{ T status } \\
\hline T1a & 76 & $19(25.0)$ & 57 \\
\hline T1b-4 & 106 & $24(22.6)$ & 82 \\
\hline \multicolumn{4}{|l|}{$\mathrm{N}$ status } \\
\hline Negative & 151 & $33(21.9)$ & 118 \\
\hline Positive & 31 & $10(32.3)$ & 21 \\
\hline \multicolumn{4}{|c|}{ Smoking history } \\
\hline Never & 75 & $18(24.0)$ & $57^{\mathrm{b}}$ \\
\hline Former & 50 & $11(22.0)$ & 39 \\
\hline Current & 57 & $14(24.6)$ & 43 \\
\hline \multicolumn{4}{|l|}{ Tumor grade $^{\mathrm{a}}$} \\
\hline G1 & 94 & $20(21.3)$ & $74^{c}$ \\
\hline $\mathrm{G} 2$ & 59 & $16(27.1)$ & 43 \\
\hline G3 & 15 & $3(20.0)$ & 12 \\
\hline \multicolumn{4}{|l|}{$\mathrm{CEA}^{\mathrm{c}}$} \\
\hline$<2.5$ & 123 & $28(22.8)$ & 95 \\
\hline$\geq 2.5$ & 57 & $15(26.3)$ & 42 \\
\hline \multicolumn{4}{|l|}{$\mathrm{SCC}^{\mathrm{a}}$} \\
\hline$<1.5$ & 140 & $34(24.3)$ & 106 \\
\hline$\geq 1.5$ & 28 & $5(17.9)$ & 23 \\
\hline \multicolumn{4}{|l|}{ CYFRA $^{\mathrm{a}}$} \\
\hline$<2.0$ & 104 & $24(23.1)$ & 80 \\
\hline$\geq 2.0$ & 74 & $19(25.7)$ & 55 \\
\hline
\end{tabular}

${ }^{\mathrm{a}}$ Unclassified patients were excluded; ${ }^{\mathrm{b}}$ never vs. former/current; ${ }^{\mathrm{c}} \mathrm{G} 1$ vs. G2-3.

IHC staining (13). The MET gene copies were determined by real-time PCR assays (13).

Statistical analyses. Statistical associations were determined by the $\chi^{2}$ test or Fisher's exact test. A multivariate logistic regression was used to evaluate independent associations. DFS and $95 \%$ confidence intervals $(95 \% \mathrm{CI})$ were evaluated by the Kaplan-Meier method comparing the different groups by logrank test. The Cox proportional hazards model was applied to the multivariate survival analysis. The odds ratio (OR) was calculated for each variable. The statistical difference was
Table II. Recurrent sites of tumors.

\begin{tabular}{llr}
\hline & \multicolumn{1}{c}{ Site } & No. \\
\hline Hematogenous & Lung & 10 \\
$(\mathrm{n}=25)^{\mathrm{b}}$ & Brain & 9 \\
& Bone & 5 \\
& Adrenal & 1 \\
Locoregional & Lymph node & 5 \\
$(\mathrm{n}=8)^{\mathrm{b}}$ & Pleural dissemination & 3 \\
\hline
\end{tabular}

${ }^{a}$ The numbers of recurrent sites overlapped. ${ }^{\mathrm{b}}$ Two, one, one and one subject had recurrent tumors in both the brain and bone, brain and adrenal, brain and pleural dissemination, and bone and lymph nodes, respectively.

Table III. Relationship between IGF1R expression and recurrence.

\begin{tabular}{lcc}
\hline Variables & \multicolumn{2}{c}{ IGF1R expression } \\
\cline { 2 - 3 } & $\begin{array}{c}\text { Positive } \\
\mathrm{n}(\%)\end{array}$ & Negative \\
\hline Cases with recurrence & $12(42.9)$ & 16 \\
Cases without recurrence & $31(20.1)$ & 123 \\
\hline
\end{tabular}

considered to be significant at $\mathrm{p}<0.05$. The data were analyzed with the Abacus Concepts, Survival Tools for Stat View software package (Abacus Concepts, Inc., Berkeley, CA, USA).

\section{Results}

Detection of IGFR1 expression and clinicopathological characteristics. Positive expression of IGFR1 was identified in 43 $(23.6 \%)$ of the 182 patients. There was no significant association between IGFR1 expression and the clinical factors (Table I).

Relationship between IGFRI expression and recurrence. The majority of the first sites of tumor recurrence were hematogenous metastases. Twenty-five and 8 cases had hematogenous (10, lung; 9, brain; 5, bone; 1, adrenal metastasis) and locoregional (4, lymph node metastasis; 3 , pleural dissemination) recurrences, respectively (Table II). The positive expression of IGFR1 was identified in $12(42.9 \%)$ of 28 patients and 31 $(20.1 \%)$ of 154 patients with and without recurrence, respectively ( $\mathrm{p}=0.009$; Table III). The univariate and multivariate logistic regression models indicated that expression of IGFR1 was an independent predictor for recurrence, as were young age and $\mathrm{N}$ status (Tables IV and V).

Influence of IGFR1 expression and clinicopathological factors on DFS. The detectable relative risk was estimated to be 2.0 with $90 \%$ statistical power. The 5-year DFS rate in patients with negative and positive IGFR1 expression was 87.6 and $70.7 \%$, respectively $(\mathrm{p}=0.007)$. Positive IGFR1 expression 
Table IV. Univariate analysis of the factors contributing to recurrence.

\begin{tabular}{lccc}
\hline Variables & Odds ratio & 95\% confidence interval & p-value \\
\hline Gender: male & 1.322 & $0.581-3.008$ & 0.506 \\
Age: $<68$ years & 2.630 & $1.151-6.007$ & 0.022 \\
Smoking history: former + current & 1.582 & $0.673-3.717$ & 0.292 \\
T status: 1b-4 & 3.056 & $1.174-7.955$ & 0.022 \\
N status: positive & 9.952 & $4.025-24.609$ & $<0.001$ \\
Tumor grade: G2-3 & 6.149 & $2.171-17.415$ & $<0.001$ \\
IGF1R expression: positive & 2.976 & $1.277-6.934$ & 0.012 \\
\hline
\end{tabular}

Table V. Multivariate analysis of the factors contributing to recurrence.

\begin{tabular}{lccc}
\hline Variables & Odds ratio & 95\% confidence interval & p-value \\
\hline Gender: male & 1.444 & $0.291-7.160$ & 0.653 \\
Age: $<68$ years & 3.981 & $1.461-10.851$ & 0.007 \\
Smoking history: former + current & 1.076 & $0.210-5.556$ & 0.927 \\
T status: 1 b-4 & 2.630 & $0.870-7.949$ & 0.087 \\
N status: positive & 10.319 & $3.623-29.389$ & $<0.001$ \\
IGF1R expression: positive & 3.153 & $1.150-8.648$ & 0.026 \\
\hline
\end{tabular}

Table VI. Univariate analysis using a proportional hazards model for disease-free survival.

\begin{tabular}{|c|c|c|c|c|c|}
\hline \multirow[t]{2}{*}{ Variables } & \multicolumn{2}{|c|}{ Characteristics } & \multirow[t]{2}{*}{$95 \%$ confidence interval } & \multirow[t]{2}{*}{ Hazard ratio } & \multirow[t]{2}{*}{ p-value } \\
\hline & Unfavorable & Favorable & & & \\
\hline Gender & Male & Female & $0.613-2.793$ & 1.309 & 0.488 \\
\hline Age (years) & $<68$ & $\geq 68$ & $1.082-4.934$ & 2.311 & 0.031 \\
\hline Smoking history & Former + Current & Never & $0.709-3.472$ & 1.567 & 0.267 \\
\hline T status & $1 b-4$ & $1 \mathrm{a}$ & $1.180-7.184$ & 2.912 & 0.020 \\
\hline $\mathrm{N}$ status & Positive & Negative & $3.704-16.667$ & 7.874 & $<0.001$ \\
\hline Tumor grade & $\mathrm{G} 2-3$ & G1 & $2.104-15.123$ & 5.642 & $<0.001$ \\
\hline IGF1R expression & Positive & Negative & $1.269-5.682$ & 2.681 & 0.001 \\
\hline
\end{tabular}

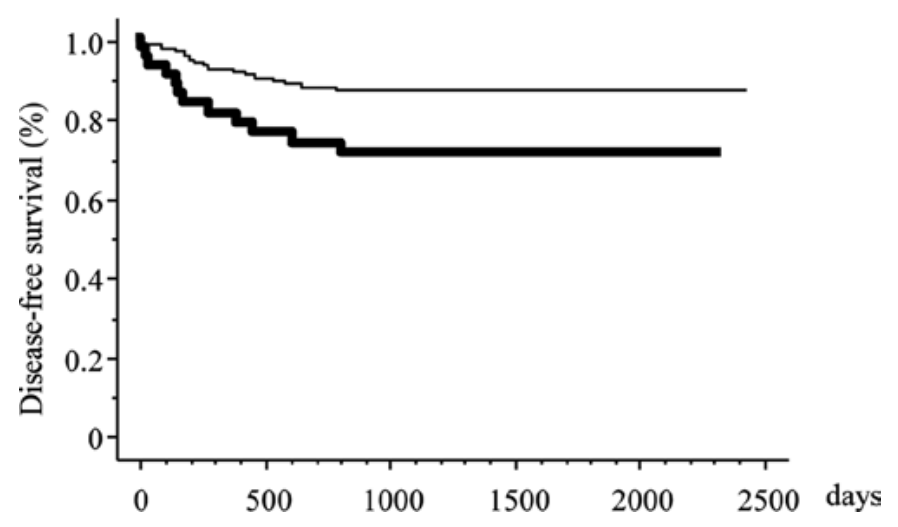

Figure 2. Kaplan-Meier DFS curves stratified by IGFR1 expression. The heavy and narrow lines indicate positive and negative expression of IGFR1, respectively. was associated with a poorer DFS according to the univariate survival analysis (Fig. 2) $(\mathrm{p}=0.001$; Table VI). A multivariate survival analysis also demonstrated that positive IGFR1 expression was independently associated with an increased risk for a poor DFS ( $\mathrm{p}=0.020$; Table VII).

Relationship between IGFR1 and molecular markers. EGFR and K-ras mutations were identified in 63 (34.6\%) and 17 (9.3\%) patients in these series, respectively. P-MET 1234/1235 and HGF were identified in 12 (6.6\%) and 104 (57.1\%) patients, respectively. MET amplification was identified only in 8 patients $(4.4 \%)$. There was no significant association of positive IGFR1 expression with the EGFR mutation, an overexpression of p-MET 1234/1235 and HGF, and MET amplification. There were significantly more tumors with 
Table VII. Multivariate analysis using a proportional hazards model for disease-free survival.

\begin{tabular}{lcccrr}
\hline Variables & \multicolumn{2}{c}{ Characteristics } & \multirow{2}{*}{$95 \%$ confidence interval } & Hazard ratio & p-value \\
\cline { 2 - 4 } & Unfavorable & Favorable & & & \\
\hline Gender & Male & Female & $0.317-3.650$ & 1.076 & 0.906 \\
Age (years) & $<68$ & $\geq 68$ & $1.222-5.686$ & 2.636 & 0.014 \\
Smoking history & Former + Current & Never & $0.318-4.132$ & 1.147 & 0.835 \\
T status & $1 \mathrm{~b}-4$ & $1 \mathrm{a}$ & $0.955-6.095$ & 2.412 & 0.063 \\
N status & Positive & Negative & $2.959-14.286$ & 6.494 & $<0.001$ \\
IGF1R expression & Positive & Negative & $1.157-5.435$ & 2.506 & 0.020 \\
\hline
\end{tabular}

Table VIII. Association among molecular markers.

\begin{tabular}{|c|c|c|c|}
\hline \multirow[t]{2}{*}{ Variables } & \multirow[t]{2}{*}{ No. of patients } & \multicolumn{2}{|c|}{ IGF1R expression } \\
\hline & & $\begin{array}{c}\text { Positive } \\
\text { n }(\%)\end{array}$ & $\begin{array}{c}\text { Negative } \\
n\end{array}$ \\
\hline Total patients & 182 & $43(23.6)$ & 139 \\
\hline \multicolumn{4}{|c|}{ EGFR mutation } \\
\hline Mutated & 63 & $17(27.0)$ & 46 \\
\hline Wild-type & 119 & $26(21.8)$ & 93 \\
\hline \multicolumn{4}{|l|}{ K-ras mutation } \\
\hline Mutated & 17 & $8(47.1)$ & 9 \\
\hline Wild-type & 165 & $35(21.2)$ & 130 \\
\hline \multicolumn{4}{|l|}{ p-MET } \\
\hline Positive & 12 & $4(33.3)$ & 8 \\
\hline Negative & 170 & $39(22.9)$ & 131 \\
\hline \multicolumn{4}{|c|}{ MET amplification } \\
\hline Positive & 8 & $0(0.00)$ & 8 \\
\hline Negative & 174 & $43(24.7)$ & 131 \\
\hline \multicolumn{4}{|c|}{ HGF expression } \\
\hline Positive & 104 & $25(24.0)$ & 79 \\
\hline Negative & 78 & $18(23.1)$ & 60 \\
\hline
\end{tabular}

IGFR1 expression among those with the K-ras mutation when compared with the wild type group ( $\mathrm{p}=0.017$; Table VIII).

\section{Discussion}

The present study revealed two significant findings. First, an increased expression of IGFR1 was significantly correlated with postoperative recurrence. Furthermore, positive IGFR1 expression was associated with a poorer DFS, thus suggesting a more aggressive tumor behavior. This finding suggests that IGFR1 expression is a suitable biomarker with which to identify those candidates who may benefit most from adjuvant chemotherapy in adenocarcinoma following a complete resection. Notably, metastatic NSCLC patients treated with gefitinib with high levels of IGF1R expression survived longer than such patients lacking expression of the protein (17). Collectively, this trend for IGF expression, similar to
Her2 status, is both a poor prognostic marker in untreated patients and a favorable predictive marker for treated patients, suggesting IGRF1 as a good molecular target. In fact, the clinical benefit of an anti-IGF1R antibody has been demonstrated in a phase II clinical study (18). The prognostic impact of IGFR1 remains controversial. Merrick et al showed that high IGFR-1 expression indicated a poor prognosis in a cohort of surgically treated NSCLC patients (8), which was consistent with the present data. On the other hand, others reported that IGFR-1 protein expression alone was not significantly associated with survival $(15,19)$. The discrepancy between these findings may be due to the number of patients analyzed, homogeneity, such as a different pathological stage, histology and the method used for IHC.

Secondly, a significant correlation was observed between positive expression of IGFR1 and K-ras mutation. These results suggest that a correlation exists between the expression status of IGFR1 and EGFR signaling, including the K-ras pathway $(20,21)$. Shen et al reported that the combination of both K-ras and IGFR1 antisense oligodeoxynucleotide cooperatively inhibited the growth of pancreatic cancer cell lines in vitro, and induced their apoptosis in vivo (22). Furthermore, combined IGF-1 and K-ras analyses have been shown to be beneficial for the better selection of colorectal cancer patients that may respond to therapy (23). Therefore, a new strategy to co-target both IGFR-1 and K-ras may be required to control lung cancers expressing IGFR1 with the K-ras mutation.

In conclusion, the present results revealed that the incidence of IGFR1 overexpression was significantly higher in recurrent cases than in non-recurrent ones. Furthermore, IGFR1 overexpression was also associated with poorer DFS. The present results therefore indicate that IGFR1 expression may be a useful marker for predicting postoperative recurrence in patients with lung adenocarcinoma following surgery.

\section{Acknowledgements}

The authors thank Misako Fukumoto and Yukiko Koyanagi for the valuable technical assistance. This study was supported, in part, by Grants-in-Aid for Scientific Research from the Ministry of Education, Culture, Sports, Science and Technology (MEXT), Japan. 


\section{References}

1. Parkin DM, Bray F, Ferlay $\mathrm{J}$ and Pisani P: Global cancer statistics, 2002. CA Cancer J Clin 55: 74-108, 2005.

2. Janssen-Heijnen ML and Coebergh JW: Trends in incidence and prognosis of the histological subtypes of lung cancer in North America, Australia, New Zealand and Europe. Lung Cancer 31: $123-137,2001$.

3. Goya T, Asamura H, Yoshimura H, Kato H, Shimokata K, Tsuchiya R, Sohara Y, Miya T and Miyaoka E: The Japanese Joint Committee of Lung Cancer Registry Prognosis of 6644 resected non-small cell lung cancers in Japan: a Japanese lung cancer registry study. Lung Cancer 50: 227-234, 2005.

4. Pignon JP, Tribodet H, Scagliotti GV, et al: Lung adjuvant cisplatin evaluation: a pooled analysis by the LACE Collaborative Group. J Clin Oncol 26: 3552-3559, 2008.

5. Kato H, Ichinose $Y$, Ohta M, Hata E, Tsubota N, Tada H, Watanabe Y, Wada H, Tsuboi M, Hamajima N and Ohta $\mathrm{M}$ : Japan Lung Cancer Research Group on Postsurgical Adjuvant Chemotherapy. A randomized trial of adjuvant chemotherapy with uracil-tegafur for adenocarcinoma of the lung. $\mathrm{N}$ Engl J Med 350: 1713-1721, 2004.

6. Khandwala HM, McCutcheon IE, Flyvbjerg A and Friend KE: The effects of insulin-like growth factors on tumorigenesis and neoplastic growth. Endocr Rev 21: 215-244, 2000.

7. LeRoith D and Roberts CT Jr: The insulin-like growth factor system and cancer. Cancer Lett 195: 127-137, 2003.

8. Merrick DT, Dziadziuszko R, Szostakiewicz B, Szymanowska A, Rzyman W, Jassem E, Jassem J, Franklin WA, Bunn PA and Hirsch FR: High insulin-like growth factor 1 receptor (IGF 1R) expression is associated with poor survival in surgically treated non-small cell lung cancer (NSCLC) patients. J Clin Oncol 25: $7550,2007$.

9. Vallières E, Shepherd FA, Crowley J, van Houtte P, Postmus PE, Carney D, Chansky K, Shaikh Z and Goldstraw P: International Association for the Study of Lung Cancer International Staging Committee and Participating Institutions. The IASLC Lung Cancer Staging Project: proposals regarding the relevance of TNM in the pathologic staging of small cell lung cancer in the forthcoming (seventh) edition of the TNM classification for lung cancer. J Thorac Oncol 4: 1049-1059, 2009.

10. Onitsuka T, Uramoto H, Nose N, Takenoyama M, Hanagiri T, Sugio K and Yasumoto K: Acquired resistance to gefitinib: the contribution of mechanisms other than the T790M, MET, and HGF status. Lung Cancer 68: 198-203, 2010.

11. Yamashita $T$, Uramoto $H$, Onitsuka $T$, Ono $K$, Baba $T$, So $T$, So T, Takenoyama M, Hanagiri T, Oyama T and Yasumoto K: Association between lymphangiogenesis-/micrometastasis- and adhesion-related molecules in resected stage I NSCLC. Lung Cancer 70: 320-328, 2010.
12. Chang MH, Lee J, Han J, Park YH, Ahn JS, Park K and Ahn MJ: Prognostic role of insulin-like growth factor receptor-1 expression in small cell lung cancer. APMIS 117: 861-869, 2009.

13. Onitsuka T, Uramoto H, Ono K, Takenoyama M, Hanagiri T, Oyama T, Izumi H, Kohno K and Yasumoto K: Comprehensive molecular analyses of lung adenocarcinoma with regard to the epidermal growth factor receptor, K-ras, MET, and hepatocyte growth factor status. J Thorac Oncol 5: 591-596, 2010.

14. Shimokawa H, Uramoto H, Onitsuka T, Iwata T, Nakagawa M, Ono $\mathrm{K}$ and Hanagiri T: TS expression predicts postoperative recurrence in adenocarcinoma of the lung. Lung Cancer: Oct. 21, 2010 (E-pub ahead of print).

15. Ludovini V, Bellezza G, Pistola L, et al: High coexpression of both insulin-like growth factor receptor-1 (IGFR-1) and epidermal growth factor receptor (EGFR) is associated with shorter disease-free survival in resected non-small-cell lung cancer patients. Ann Oncol 20: 842-849, 2009.

16. Uramoto H, Sugio K, Oyama T, Ono K, Sugaya M, Yoshimatsu T, Hanagiri T, Morita M and Yasumoto K: Epidermal growth factor receptor mutations are associated with gefitinib sensitivity in non-small cell lung cancer in Japanese. Lung Cancer 51: 71-77, 2006.

17. Cappuzzo F, Toschi L, Tallini G, et al: Insulin-like growth factor receptor 1 (IGFR-1) is significantly associated with longer survival in non-small-cell lung cancer patients treated with gefitinib. Ann Oncol 17: 1120-1127, 2006.

18. Karp DD, Paz-Ares LG, Novello S, et al: Phase II study of the anti-insulin-like growth factor type 1 receptor antibody CP-751,871 in combination with paclitaxel and carboplatin in previously untreated, locally advanced, or metastatic non-smallcell lung cancer. J Clin Oncol 27: 2516-2522, 2009.

19. Cappuzzo F, Tallini G, Finocchiaro G, et al: Insulin-like growth factor receptor 1 (IGF1R) expression and survival in surgically resected non-small-cell lung cancer (NSCLC) patients. Ann Oncol 21: 562-567, 2010.

20. Lee AV, Cui X and Oesterreich S: Cross-talk among estrogen receptor, epidermal growth factor, and insulin-like growth factor signaling in breast cancer. Clin Cancer Res 7: 4429-4435, 2001.

21. Gilmore AP, Valentijn AJ, Wang P, Ranger AM, Bundred N, O'Hare MJ, Wakeling A, Korsmeyer SJ and Streuli $\mathrm{CH}$ : Activation of BAD by therapeutic inhibition of epidermal growth factor receptor and transactivation by insulin-like growth factor receptor. J Biol Chem 277: 27643-27650, 2002.

22. Shen YM, Yang XC, Yang $C$ and Shen JK: Enhanced therapeutic effects for human pancreatic cancer by application K-ras and IGF-IR antisense oligodeoxynucleotides. World J Gastroenterol 14: 5176-5185, 2008.

23. Scartozzi M, Mandolesi A, Giampieri R, et al: Insulin-like growth factor 1 expression correlates with clinical outcome in K-RAS wild-type colorectal cancer patients treated with cetuximab and irinotecan. Int J Cancer 127: 1941-1947, 2010. 